\title{
TRATAMENTO DE TRAUMATISMO CRANIOENCEFÁLICO EM Nasua nasua (Linnaeus, 1766): Relato de caso
}

\author{
(Traumatic brain treatment in Nasua nasua - case report)
}

\begin{abstract}
${ }^{1}$ Maria Eduarda de Quadros Soares, ${ }^{1}$ Júlia Vieira Herter, Cecília Haarengl de Souza Braz, ${ }^{1}$ Guilherme Mazocante de Oliveira, ${ }^{1}$ Lenon Silva Lemos de Oliveira, ${ }^{2}$ Sofia Silva La Rocca de Freitas, ${ }^{1}$ Líria Queiroz Luz Hirano $^{7}$
\end{abstract}

${ }^{1}$ Universidade de Brasília - UnB, Brasil. ${ }^{2}$ União Pioneira de Integração Social - UPIS, Brasília, Brasil.

*Correspondência: eduarda.qsoares@gmail.com

Resumo: Animais silvestres podem ser expostos a diversas agressões de caráter traumático, como por exemplo, quedas, atropelamentos e predação. Tais eventos podem originar diversas lesões, dentre elas, o traumatismo cranioencefálico (TCE), que é definido como um trauma na cabeça que afeta o SNC (CUNHA, 2017). O objetivo deste trabalho é relatar um caso de TCE em um quati (Nasua nasua). Foi atendido um exemplar de quati macho, jovem, no Setor de Animais Silvestres do Hospital Veterinário da Universidade de Brasília, que apresentava hipoatividade e hiporreflexia. Ao exame físico, foi observada fissura no palato em região média e laceração em região de face. A imagem radiográfica permitiu observar fratura no osso frontal e confirmou a fissura no palato. A abordagem terapêutica inicial foi realizada com fluidoterapia com ringer lactato (50 mL, SC, dose única), manitol $20 \%$ (5 mg/kg, IV, BID) e tramadol $50 \mathrm{mg} / \mathrm{mL}(6 \mathrm{mg} / \mathrm{kg}$, IM, BID) por quatro dias. Concomitantemente, houve a utilização de meloxicam $0,2 \%(0,1$ $\mathrm{mg} / \mathrm{kg}, I M, S I D)$ e dipirona $500 \mathrm{mg} / \mathrm{mL}(25 \mathrm{mg} / \mathrm{kg}, V O, B I D)$ por dez dias. No sexto dia de tratamento, iniciou-se o uso de propentofilina $10 \mathrm{mg} / \mathrm{mL}$ ( $3 \mathrm{mg} / \mathrm{kg}, \mathrm{VO}, \mathrm{BID}$ ) por quinze dias. Houve melhora do quadro clínico após o terceiro dia de tratamento. Não ocorreu intervenção cirúrgica para a fratura de palato, que não interferia na alimentação do paciente, nem para a fratura do osso frontal, que foi estabilizada com bandagens e cicatrizou por segunda intenção. Após dois meses, o animal foi considerado apto para retorno à natureza e encaminhado ao CETAS-DF para soltura. No TCE ocorre ativação de vias bioquímicas que intensificam os danos e elevam a pressão intracraniana, que compromete a perfusão encefálica e é considerada a principal causa de óbito. Para uma melhor terapêutica recomenda-se exames neurológicos e de imagem. A prioridade deve ser a estabilização crânio-cervical, além da manutenção de pressão de perfusão cerebral e suprimento de oxigênio adequados. Evitar a hipovolemia, a hipóxia e a hiperglicemia são essenciais para um melhor prognóstico. O manitol possui efeito osmótico, então diminui a viscosidade sanguínea e induz a diurese, o que promove vasoconstrição cerebral e reduz o risco de edema cerebral, mas possui efeito de desidratação, que foi compensado com a fluidoterapia, realizada de forma subcutânea devido ao alto volume de administração e a facilidade de administração da via. Já a propentofilina auxilia no aumento da perfusão sanguínea e consequente oxigenação cerebral. O controle da dor também está ligado diretamente à diminuição da $\mathrm{PIC}$, por isso analgésicos e anti-inflamatórios não esteroidais são recomendados na terapêutica do TCE. O uso de opioides pode causar efeitos adversos, como hipotensão, depressão respiratória e aumento da PIC, porém quando utilizado com doses analgésicas são considerados seguros. Em casos graves, a intervenção cirúrgica pode ser recomendada (SANDE; WEST, 2010). O tratamento de TCE deve ser imediato e agressivo, pois apesar do prognóstico reservado, os animais podem se recuperar de forma sistêmica e neurológica se as anormalidades forem identificadas precocemente, conforme o quati deste presente relato.

Palavras-chave: manitol; quati; terapêutica; injúria; trauma. 


\section{Referências}

CUNHA, D. S. Politraumatismo em cachorro-do-mato (Cerdocyon thous) por provável atropelamento. Orientador: Prof. Dr. Danilo Simonini Teixeira. 2017. 36 p. Trabalho de conclusão de curso (Graduação em Medicina Veterinária) - Universidade de Brasília/Faculdade de Agronomia e Medicina Veterinária, [S. l.], 2017. Disponível em: https://bdm.unb.br/handle/10483/17956. Acesso em: 23 ago. 2020.

SANDE, A.; WEST, C. Traumatic brain injury: a review of pathophysiology and management. Journal of Veterinary Emergency and Critical Care, [s. I.], v. 20, n. 2, p. 177-190, 2010. DOI 10.1111/j.1476-4431.2010.00527.x. Disponível em: pubmed.ncbi.nlm.nih.gov/20487246/. Acesso em: 21 ago. 2020 